Вестник Евразийской науки / The Eurasian Scientific Journal https://esj.today

2021, №5, Том 13 / 2021, No 5, Vol 13 https://esj.today/issue-5-2021.html

URL статьи: https://esj.today/PDF/38ECVN521.pdf

DOI: 10.15862/38ECVN521 (https://doi.org/10.15862/38ECVN521)

Ссылка для цитирования этой статьи:

Сун, Ц. Российско-китайское финансовое сотрудничество: возможность крупномасштабного углубления / Ц. Сун // Вестник евразийской науки. — 2021. — Т. 13. — № 5. — URL: https://esj.today/PDF/38ECVN521.pdf DOI: $10.15862 / 38 E C V N 521$

For citation:

Song J. Russian-Chinese financial cooperation: possibility of large-scale deepening. The Eurasian Scientific Journal, 13(5): 38ECVN521. Available at: https://esj.today/PDF/38ECVN521.pdf. (In Russ., abstract in Eng.). DOI: $10.15862 / 38 \mathrm{ECVN} 521$

Статья спонсирована Советом стипендиальных программ Китая (The article is sponsored by the China Scholarship Council)

\title{
Сун Цзясюе
}

ФГАОУ ВО «Уральский федеральный университет имени первого Президента России Б.Н. Ельцина», Екатеринбург, Россия Аспирантка

\section{Российско-китайское финансовое сотрудничество: возможность крупномасштабного углубления}

Аннотация. Россия и Китай сегодня являются двумя крупнейшими развивающимися экономиками в мире, и также являются всесторонними партнерами друг друга, имеющие тесные связи и сотрудничество в политической, экономической, энергетической и других областях. В последние годы Россия и Китай достигли больших результатов в финансовом сотрудничестве, но в целом ситуация все еще находится в зачаточном состоянии. Крупномасштабное углубление российско-китайского финансового сотрудничества является общим интересом и неизбежной тенденцией двух стран.

В данной статье авторы сначала рассмотрели состояния текущего российско-китайского финансового сотрудничества. Установлено, что две страны создали двухуровневый механизм сотрудничества, открыли несколько банковских филиалов и представительств, развивали межбанковские корреспондентские отношения и двусторонние расчеты в национальных валютах быстро развиваются, доля национальных валют в расчетах между Россией и Китаем в 2020 году достигла $25 \%$, а в 2013-2014 годах эта доля была ничтожна и составляла порядка $2-3 \%$.

Авторы еще с точки зрения корреляции экономического шока SVAR-модель используется для анализа возможности крупномасштабного углубления финансового сотрудничества между Россией и Китаем. Установлено, что коэффициенты корреляции шока предложения и шока спроса между Россией и Китаем не превысили 0,2. Считается, что у двух стран есть базовые условия для финансового сотрудничества, но в настоящее время нет условий для крупномасштабного углубления дальнейшего сотрудничества в финансовой сфере.

В заключении статьи авторы рекомендовали углублять российско-китайское финансовое сотрудничество со следующих аспектов: 
1. Совершенствование механизма финансового сотрудничества.

2. Повышение уровня двусторонних расчетов в нацвалютах и содействие интернационализацию рубля и юаня.

3. Повышение уровня обслуживания банков и внедрение инновации в финансовые продукты.

Ключевые слова: финансовое сотрудничество; Россия; Китай; SVAR-модель; экономический шок; шок предложения; шок спроса; корреляция

\section{Введение}

Россия и Китай сегодня являются двумя крупнейшими развивающимися экономиками в мире, и также являются всесторонними партнерами друг друга, имеющие тесные связи и сотрудничество в политической, экономической, энергетической и других областях. Сотрудничество между Россией и Китаем в сферах экономики и торговли, валюты и финансов, строительства инфраструктуры развивается на протяжении длительного периода времени.

В 2013 году Председатель Китая Си Цзиньпин предложил построить Экономический пояс Шелкового пути, в котором финансовое сотрудничество является важной частью. Углубление финансового сотрудничества является не только важной поддержкой финансирования инициативы "Один пояс, один путь" 1 , но и важным способом создания новой модели международной финансовой системы. В 2015 году литеры России и Китая подписали соглашение о совместном строительстве Экономического пояса Шелкового пути и Евразийского экономического союза, что больше способствовало дальнейшему развитию финансового сотрудничества между Китаем, Россией и другими государствами-членами альянса.

Исходя из общего интереса России и Китая, углубление финансового сотрудничества между двумя странами будет способствовать экономическому и торговому развитию, повышению общего уровня экономического развития и даже развитию денежно-кредитного и финансового сотрудничества между Россией и Китаем и странами Евразийского экономического союза.

\section{Состояние российско-китайского финансового сотрудничества}

После нескольких лет развития, российско-китайское финансовое сотрудничество уже достигло определенных результатов.

1. Сформирован двухуровневый механизм сотрудничества, включающий государственный уровень и негосударственный уровень.

Рамки механизма сотрудничества на государственном уровне также можно разделить на центральный уровень и местный уровень. Центральный уровень включает механизм регулярных встреч глав правительств России и Китая и механизм диалога министров финансов двух стран, который в основном обеспечивает политическую поддержку двустороннего финансового сотрудничества и играет координирующую и содействующую роль в двустороннем сотрудничестве. Для координации работы механизма центрального уровня был

1 Инициатива «Один пояс, один путь» по созданию глобальной транспортной и инвестиционной инфраструктуры "Один пояс, один путь" объединяет два проекта — "Экономический пояс Шелкового пути" и "Морской Шелковый путь XXI века". 
создан Комитет по регулярным встречам глав правительств и 19 подкомитетов, среди которых Подкомиссия по сотрудничеству в финансовом сфере и Межправительственная комиссия поинвестиционному сотрудничеству Китая и России являются важными частей механизма и профессиональными платформами для финансового сотрудничества и инвестиционного сотрудничества [1].

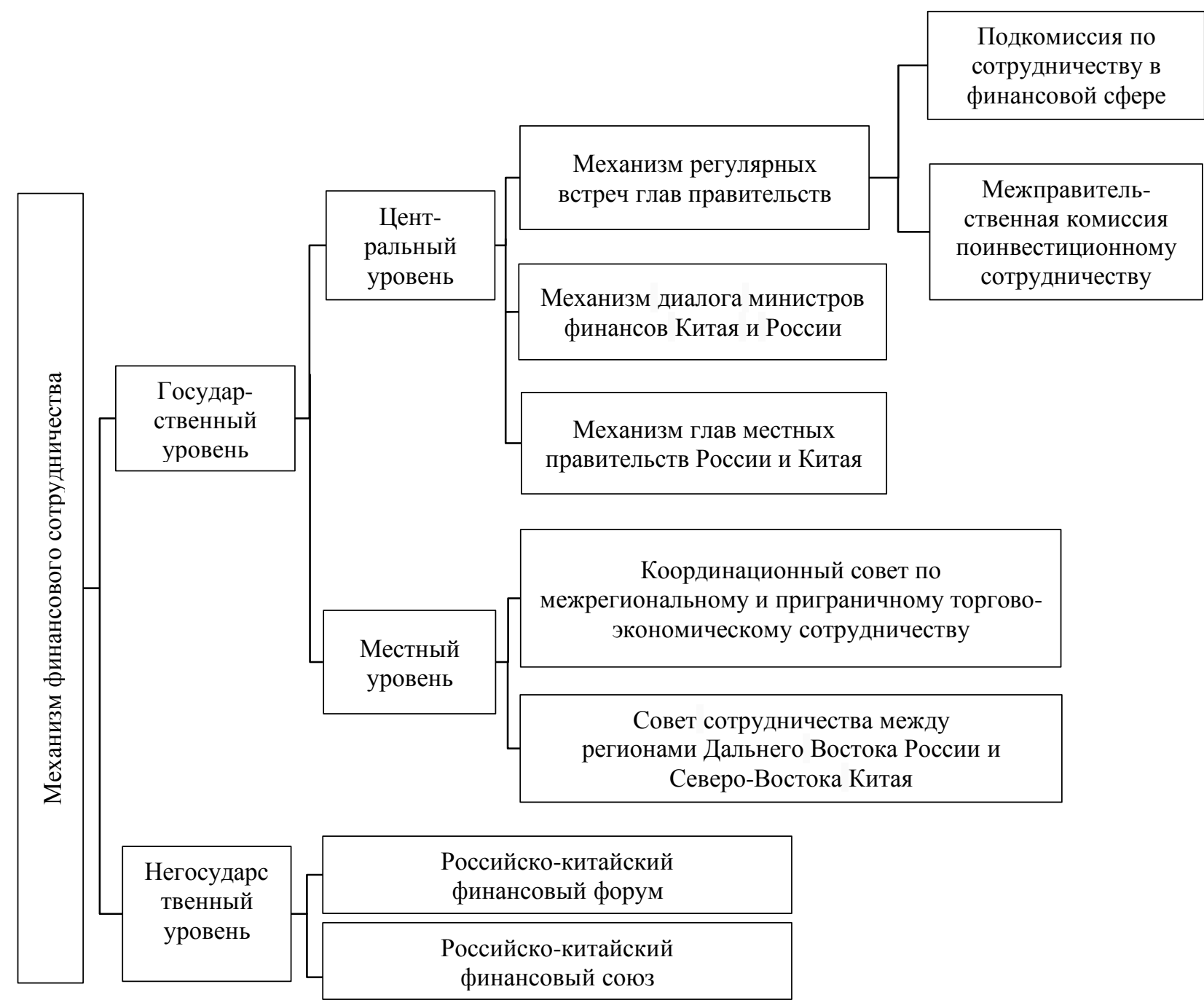

\section{Рисунок 1. Механизм финансового \\ сотрудничества между Россией и Китаем (составлено авторами)}

Механизм на местном уровне состоит из механизма встреч глав местных правительств России и Китая, российско-китайского координационного совета по межрегиональному и приграничному торгово-экономическому сотрудничеству и межправительственной россйско-китайской комиссии по сотрудничеству и развитию Дальнего Востока и Байкальского региона России и Северо-Востока Китая ${ }^{2}$. Хотя ни один из них не является специализированным механизмом финансового сотрудничества, они создали для развития местного финансового сотрудничества условия и основные платформы.

${ }^{2}$ В мае 2015 года был создан Местный совет сотрудничества Дальнего Востока России и СевероВосточного Китая, который в 2017 году был преобразован в Межправительственный комитет по сотрудничеству Дальнего Востока России и Байкальского региона и Северо-Восточного Китая. 
На негосударственном уровне в основном включает российско-китайский Форум финансового сотрудничества и российско-китайский финансовый союз, которые играют важную роль в продвижении обменов и развитии финансового сотрудничества между финансовыми учреждениями двух стран. Российско-китайский финансовый союз является первой неофициальной платформой по содействию обменам и сотрудничеству финансовых структур между Россией и Китаем. По состоянию на 2019 год число членов союза с 35 выросло до 72. Среди них 34 китайского члена и 38 российских членов. Члены союза охватывают более десяти типов финансовых учреждений, таких как банки, трасты, фонды, страховые компании, компании по управлению активами, финансовый лизинг, отраслевые ассоциации, рейтинговые агентства и консалтинговые компании ${ }^{3}$.

\section{2. Сотрудничество в банковской сфере между Россией и Китаем.}

Межбанковское сотрудничество является одним из важных элементов российскокитайского финансового сотрудничества.

В декабре 2015 года председатель Банка России и председатель Народного банка Китая подписали в Пекине меморандум о взаимопонимании между двумя центральными банками, активно реализуя важный консенсус, достигнутый главами двух стран по углублению двустороннего финансового сотрудничества.

В связи с быстрым развитием России и Китая в области экономики, торговли и инвестиций было оказано содействие развитию межбанковского сотрудничества между двумя странами. Сотрудничество в основном включает открытие филиалов и представительств, развитие межбанковских корреспондентских отношении, финансирования, трансграничных денежных переводов и платежных систем банковской картой и другие [2].

К концу 2018 года китайские банки установили корреспондентские отношения с более чем 200 российскими банками и создали клиринговую сеть, включающую доллары США, рубли и юани. В настоящее время 9 российских банков открыли 1 филиал и 10 представительств в Китае, 6 китайских банков создали 6 филиалов и 2 представительства в России. В 2017 году банк России в Пекине открыл первое представительство за рубежом.

Таблица 1

\section{Структурные подразделения российских банков в Китае}

\begin{tabular}{|l|l|c|}
\hline \multicolumn{1}{|c|}{ Название банка } & \multicolumn{1}{|c|}{ Структура } & Дата создания \\
\hline \multirow{2}{*}{ Банк ВТБ } & г. Пекин, представительство & 09.1989 г. \\
\cline { 2 - 3 } & г. Шанхай, филиал банка & 04.2007 г. \\
\hline Банк российский кредит & г. Пекин, представительство & 04.1999 г. \\
\hline Внешэкономбанк & г. Пекин, представительство & 03.2004 г. \\
\hline Промсвязьбанк & г. Пекин, представительство & 07.2006 г. \\
\hline Газпромбанк & г. Пекин, представительство & 08.2008 г. \\
\hline МДМ Банк & г. Пекин, представительство & 07.2009 г. \\
\hline Еврофинанс Моснарбанк & г. Пекин, представительство & 06.2010 г. \\
\hline Сбербанк России & г. Пекин, представительство & 06.2015 г. \\
\hline Россельхозбанк & г. Пекин, представительство & $03.2017 г$. \\
\hline Банк России & г. Пекин, представительство & \\
\hline
\end{tabular}

Составлено авторами на основе источников [1; 3]

${ }^{3}$ Юй Линшуан: Российско-китайский финансовый союз: укрепит финансовые связи и построит "золотой мост" между Россией и Китаем. Международный онлайн Хэйлунцзян. [Электронный pecypc]. - URL: https://www.163.com/dy/article/EPTIJPR305417431.html (дата обращения: 12.09.2021). 


\section{Структурные подразделения китайских банков в России}

\begin{tabular}{|c|c|c|}
\hline Название банка & Структура & $\begin{array}{c}\text { Дата } \\
\text { создания }\end{array}$ \\
\hline \multirow{3}{*}{ Банк Китая } & г. Москва, филиал банка & 04.1993 г \\
\hline & г. Хабаровск, филиал банка & $06.2012 \Gamma$ \\
\hline & г. Владивосток, филиал банка & 01.2013 г. \\
\hline Экспортно-импортный банк Китая (Эксимбанк) & г. Санкт-Петербург, представительство & $06.2007 \Gamma$ \\
\hline Промышленно-торговый банк Китая (АйСиБиСи Банк) & г. Москва, филиал банка & $11.2007 \Gamma$ \\
\hline Банк развития Китая & г. Москва, представительство & 09.2010 г. \\
\hline Строительный банк Китая & г. Москва, филиал банка & 03.2013 г \\
\hline Сельскохозяйственный банк Китая & г. Москва, филиал банка & 01.2015 г. \\
\hline
\end{tabular}

Составлено авторами на основе источников [1; 3]

Банки двух сторон также активно сотрудничают в сфере платежных систем банковской картой. На российском рынке банковские карты China UnionPay впервые появились в 2007 году. С этого времени держатели карт UnionPay могли получать наличные денежные средства в банкоматах, оплачивать товары и услуги, но были лишены возможности пополнять карточные счета. Карты данной системы в основном были востребованы и обслуживались на востоке России ${ }^{4}$. С сентября 2013 года UnionPay пришла в Россию - ООО «ЮнионПэй» включено в реестр операторов платёжных систем РФ, и в это время эмиссия карт на территории России началась.

В 2014 году из-за украинского кризиса международные платежные системы Visa и MasterCard временно приостановили оказание услуг в России, что косвенно способствовало продвижению карт China UnionPay на российском рынке.

В 2014 году банк «Восточный» и компания UnionPay International приступили к выпуску совместных карт в Харбине, позволяя использовать такие карты в провинции Хэйлунцзян. В 2017 году Россельхозбанк впервые в России выпустил кобейджинговую карту двух национальных платежных систем "Мир"-UnionPay. При этом уточняется, что держателю карты "Мир"-UnionPay доступны функции снятия и внесения денежных средств в банкоматах и пунктах выдачи наличных, оплаты товаров и услуг, а также совершения других платежных операций в рамках российской инфраструктуры карт "Мир" и в 162 странах, где принимаются карты UnionPay [4].

В 2019 году в России более 715 тысяч торговых точек принимают к оплате карты Union Pay. По данным сайта China UnionPay, по состоянию на август 2020 года в России было выпущено более 3,3 миллиона карт.

\section{3. Сотрудничество в области расчетов в национальных валютах.}

В 2002 г. центральными банками России и Китая подписано "Соглашение о проведение расчетов в национальных валютах по пограничной торговле". В 2003 году китайский город Хэйхэ стал пилотным городом для проведения расчетов в национальных валютах и Россия и Китая официально начали переходить на национальные валюты в расчетах.

С 2003 по 2008 год развитие двусторонних расчетов в национальных валютах находилось на стадии испытаний. За этот период объем расчетов в национальных валютах увеличился в 54 раза, из которых расчеты в рублях составил 29,081 миллиона долларов США, расчеты в юанях составил 16,62 миллиона долларов США. Объем расчетов в рублях был в 175

${ }^{4}$ Карты платежной системы China UnionPay. [Электронный pecypc] — URL: https://bankirsha.com/kartyplatezhnoy-sistemy-china-unionpay.html (дата обращения: 16.09.2021). 
раз больше, чем объем расчетов в юанях ${ }^{5}$. На данном этапе расчет в рублях составлял относительно высокую долю, в основном из-за того, что китайско-российская приграничная торговля в основном основана на китайском экспорте.

Период с 2009 по 2013 год — второй этап. 22 ноября 2010 года Китай начал прямую торговлю российскими рублями на межбанковском рынке, 15 декабря самого года Московская биржа начала торги с юанем, с тех пор расчеты в национальных валютах между двумя странами значительно возросли, особенно расчеты в юанях. В 2011 году представители Центрального банка России и Народного банка Китая подписали новое соглашение о расчетах и платежах в национальных валютах, которое предоставляло законодательную возможность осуществлять расчеты и платежи за товары и услуги между субъектами РФ и Китая как в свободно конвертируемых валютах, так и в рублях и юанях ${ }^{6}$. В 2013 году объем расчетов в национальных валютах достиг 986 миллионов долларов США, из которых объем расчетов в юанях достиг 517 миллионов долларов США, что составляет 52,4 \% [1].

С 2014 года до сих пор это был третий этап, и взаиморасчеты в нацвалютах продолжают наращивать. В целях углубления развития расчетов в нацвалютах Банк России и Народный банк Китая в 2014 году подписали соглашение о свопе в национальных валютах на три года, объем своп-линии составляет 150 млрд юаней ${ }^{7}$.

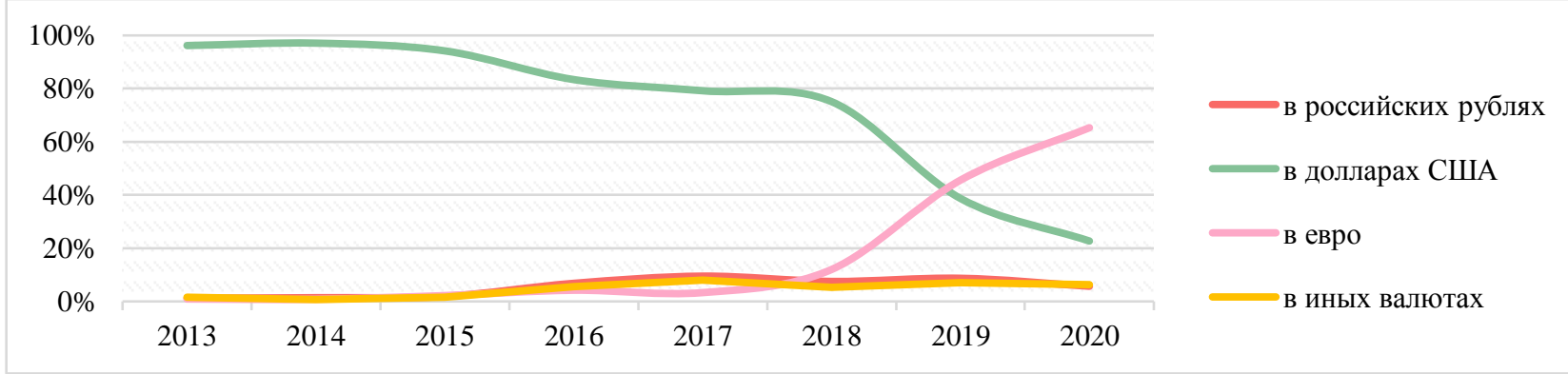

Рисунок 2. Валютная структура поступлений в Россию из Китая (составлено авторами на основе данных Банк России ${ }^{8}$ )

Хотя Россия и Китай давно сотрудничают в расчетах в нацвалютах, но в 2015 году доля американской валюты в двусторонних сделках все еще составляла около 90 процентов. Но затем позиции американской валюты начали заметно слабеть. В 2019 году фактически с момента старта торговых войн между США и КНР - ситуация кардинально поменялась: по его итогам доля доллара в расчетах между России и Китая рухнула до 51 \%. В 2020 году американская валюта продолжила сдавать позиции. В первом квартале она заняла $46 \%$ российско-китайского торгового оборота: впервые доля доллара составила менее $50 \%$ \%

${ }^{5}$ Китайско-российская торговля открыла эру расчетов в национальных валютах, и в настоящее время нет никаких преимуществ. Чайна Бизнес таймс (China Business Times). [Электронный pecypc]. - URL: http://www.arbitrationlawyer.cn/html/4238.html (дата обращения: 12.09.2021).

6 Зыкова Т., Поносов И. Рубль для Поднебесной: в Китае можно будет расплачиваться российскими пластиковыми картами. [Электронный ресурс]. — URL: https://rg.ru/2011/06/23/dengi-site.html (дата обращения: 16.09.2021).

${ }^{7}$ В 2017 году этот валютный своп был пролонгирован еще на три года.

${ }^{8}$ Официальный сайт Банка России. Статистика внешнего сектора. [Электронный ресурc]. — URL: https://cbr.ru/statistics/macro_itm/svs/ (дата обращения: 17.09.2021).

${ }^{9}$ Гринкевич Д. Юань брал: доллар впервые занял менее 50 \% в торговле России с КНР. [Электронный pecypc]. - URL: https://e-news.su/in-world/342347-yuan-bral-dollar-vpervye-zanyal-menee-50-v-torgovle-rossii-sknr.html (дата обращения: 16.09.2021). 
Взаиморасчеты между Россией и Китаем и их структура представлены на рисунках 2, 3.

Судя по ситуации с поступлениями в Россию (рис. 2), расчетами в рублях и иных валютах (это именно китайские юани, далее юань), хотя наблюдается тенденция к росту, она не очевидна. Ситуация с перечислениями из России в Китай (рис. 3) немного иная, наблюдается увеличение доли расчетов в юанях до $25 \%$, менее чем за семь лет показатель вырос почти в десять раз, следует понимать, что в 2013-2014 годах эта доля была ничтожна и составляла порядка $2-3 \%$.

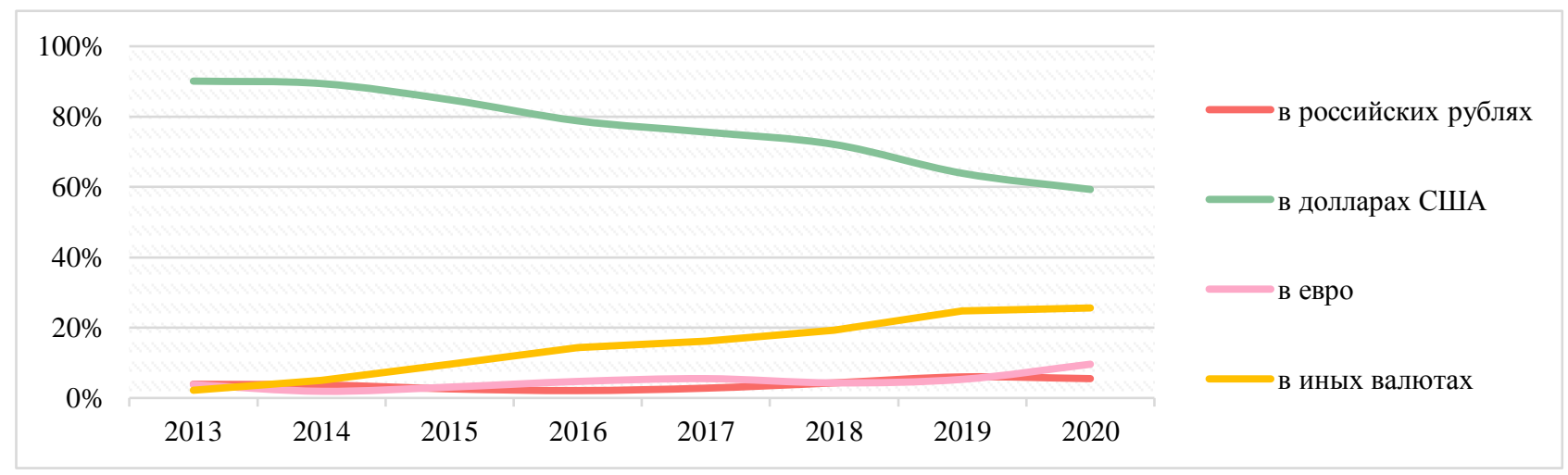

Рисунок 3. Валютная структура перечислений из России в Китай (составлено авторами на основе данных Банк России)

На рисунках 2 и 3 видно, что расчеты в долларах США снижаются из года в год, рассчитав в рублях и в юанях растут, можно говорить о том, что Россия и Китая уходит от расчетов в долларах США, а расчеты в нац. валютах между Россией и Китаем развивается. Можно обнаружить, что Китай и Россия активно развивают расчеты в нац. валютах и способствуют дедолларизации.

Дедолларизация соответствует стратегическим интересам сторон, может способствовать всестороннему сотрудничеству и предоставить двум странам возможность смягчать контроль в финансовой сфере. Учитывая установившиеся прочные экономические связи между двумя странами, есть основания рассчитывать на дальнейшее углубление связей и расширение сотрудничества в финансовой сфере [5].

Китай и Россия достигли определенных результатов в области финансового сотрудничества, но в целом находится в зачаточном состоянии и все еще нуждается в дальнейшем развитии. Поэтому дальше в данной статье использована модель SVAR для анализа возможности углубления китайско-российского финансового сотрудничества в больших масштабах.

\section{Методология}

Модель VAR является относительно зрелой моделью для описания экономических шоков. VAR модели достаточно просты в использовании, но и характеризуются более высокой точностью прогноза. Однако поскольку данные модели не имеют каких-либо структурных или идентификационных ограничений на параметры, их экономической обоснованности слабой. Для решения данной проблемы в 1990-х годах активно развивалась структурная векторная авторегрессия, и стала применяться на практике для анализа и прогнозирования макроэкономических показателей [6].

В применении теорию корреляции экономического шока для эконометрического анализа, Blanchard O. и Quah D. впервые применили модель VAR и теорию корреляции 
экономического шока к макроэкономическому анализу в 1989 году. Они представили долгосрочные шоки в модели VAR и разделили экономические шоки на шоки предложения и на шоки спроса. Проанализировали влияние шока предложения и шока спроса на послевоенную экономику США [7].

Bayoumi T. и Eichengreen B. также использовали эту модель, когда они изучали оптимальную валютную зону, и применили к модели долгосрочное ограничение, которое было преобразовано в легко оцениваемую модель SVAR. Они использовали объем производства и цену в качестве двух переменных для изучения симметрии экономических шоков в экономиках и сравнили симметрии различных экономик, а затем изучают, подходят ли эти экономики для создания оптимальных валютных зон [8].

Структурная векторная авторегрессионная модель с гистерезисом первого порядка двух переменных запишем SVAR в общем виде [9]:

$$
\begin{aligned}
& y_{t}=\beta_{10}+c_{12} p_{t}+\beta_{11} y_{t-1}+\beta_{12} p_{t-1}+\varepsilon_{s t}, \\
& p_{t}=\beta_{20}+c_{21} y_{t}+\beta_{21} y_{t-1}+\beta_{22} p_{t-1}+\varepsilon_{d t},
\end{aligned}
$$

где $t=1,2,3 \ldots T$, $\varepsilon_{s t}$ и $\varepsilon_{d t}$ белый шум, предполагая дисперсию $\delta^{2}{ }_{y}=\delta^{2}{ }_{p}=1$, и нет корреляции между $\varepsilon_{s t}$ и $\varepsilon_{d t}$.

Преобразуя приведенную SVAR-модель (1), (2) в матричное уравнение, чтобы получить следующую формулу:

$$
\left[\begin{array}{cc}
1 & -c_{12} \\
-c_{21} & 1
\end{array}\right]\left[\begin{array}{l}
y_{t} \\
p_{t}
\end{array}\right]=\left[\begin{array}{l}
\beta_{10} \\
\beta_{20}
\end{array}\right]+\left[\begin{array}{ll}
\beta_{11} & \beta_{12} \\
\beta_{21} & \beta_{22}
\end{array}\right]\left[\begin{array}{l}
y_{t-1} \\
p_{t-1}
\end{array}\right]+\left[\begin{array}{l}
\varepsilon_{s t} \\
\varepsilon_{d t}
\end{array}\right]
$$

Если $C_{0}=\left[\begin{array}{cc}1 & -c_{12} \\ -c_{21} & 1\end{array}\right], \quad X_{t}=\left[\begin{array}{l}y_{t} \\ p_{t}\end{array}\right], \quad D_{0}=\left[\begin{array}{l}\beta_{10} \\ \beta_{20}\end{array}\right], \quad D_{1}=\left[\begin{array}{ll}\beta_{11} & \beta_{12} \\ \beta_{21} & \beta_{22}\end{array}\right], \quad \varepsilon_{t}=\left[\begin{array}{l}\varepsilon_{s t} \\ \varepsilon_{d t}\end{array}\right]$, то матричная формула (3) может быть представлена в приведенной форме:

$$
C_{0} X_{t}=D_{0}+D_{1} X_{t-1}+\varepsilon_{t} .
$$

Если $C_{0}$ является обратимой матрицей, то получим:

$$
X_{t}=C_{0}^{-1} D_{0}+C_{0}^{-1} D_{1} X_{t-1}+C_{0}^{-1} \varepsilon_{t} .
$$

Игнорируя постоянные члены и внося итеративные изменения, модель SVAR с двумя переменными может быть записана как модель скользящего среднего бесконечного порядка, получим следующую формулу:

$$
X_{t}=C_{0}^{-1} \varepsilon_{t}+C_{0}^{-1} D_{1} C_{0}^{-1} \varepsilon_{t-1}+\left(C_{0}^{-1} D_{1}\right)^{2} C_{0}^{-1} \varepsilon_{t-2}+\left(C_{0}^{-1} D_{1}\right)^{3} C_{0}^{-1} \varepsilon_{t-3}+\cdots
$$

Допустим, что $C_{0}^{-1}=A_{0}, C_{0}^{-1} D_{1} C_{0}^{-1}=A_{1}, \quad\left(C_{0}^{-1} D_{1}\right)^{2} C_{0}^{-1}=A_{2}$, тогда выражение (6) можно переписать представить следующим образом:

$$
X_{t}=A_{0} \varepsilon_{t}+A_{1} \varepsilon_{t-1}+A_{2} \varepsilon_{t-2}+\cdots=\sum_{i=1}^{\infty} L^{i} A_{i} \varepsilon_{t},
$$

где $L^{i}$ - лаговый оператор, матрицы $A_{i}$ представляют собой функции импульсного отклика толчков на элементы $X_{t}$.

Пусть $X_{t}=\left[\begin{array}{l}y_{t} \\ p_{t}\end{array}\right], \quad \varepsilon_{t}=\left[\begin{array}{l}\varepsilon_{s t} \\ \varepsilon_{d t}\end{array}\right]$, получаем в следующем виде:

$$
\left[\begin{array}{l}
y_{t} \\
p_{t}
\end{array}\right]=\sum_{i=1}^{\infty} L^{i}\left[\begin{array}{ll}
a_{11 i} & a_{12 i} \\
a_{21 i} & a_{22 i}
\end{array}\right]\left[\begin{array}{l}
\varepsilon_{s t} \\
\varepsilon_{d t}
\end{array}\right]
$$


Здесь $y_{t}$ и $p_{t}$ - все стабильные случайные процессы, а $\varepsilon_{s t}$ и $\varepsilon_{d t}$ представляют собой белые шумы, представляющие фактические шоки предложения и шоки спроса, $a_{11 i}$ представляет собой элемент $a_{11}$ в матрице $A_{i}$.

Согласно теории корреляции экономических шоков, долгосрочное ограничение в модели может быть выражено следующим образом: шоки предложения имеют постоянное влияние на уровень производства, шоки спроса имеют только временное влияние, и следует ограничение [8]:

$$
\sum_{i=1}^{\infty} a_{11 i}=0 .
$$

Модель, определяемая уравнениями (7) и (9), может быть оценена с использованием векторной авторегрессии. Каждый элемент $X_{t}$ регрессируется на запаздывающих значениях всех элементов $X$. Используя матрицы В для представления этих коэффициентов оценки, векторная авторегрессия может быть записана в следующем форме [8]:

$$
\begin{aligned}
X_{t}=B_{1} X_{t-1} & +B_{2} X_{t-2}+\cdots+B_{n} X_{t-n}+e_{t} \\
& =B(L) X_{t-1}+e_{t} \\
& =[I-B(L)]^{-1} e_{t} \\
=e_{t} & +D_{1} e_{t-1}+D_{2} e_{t-2}+\cdots
\end{aligned}
$$

Формула (9) можно представлять в следующем матричном виде:

$$
\left[\begin{array}{l}
y_{t} \\
p_{t}
\end{array}\right]=\left[\begin{array}{ll}
b_{11}(L) & b_{12}(L) \\
b_{21}(L) & b_{22}(L)
\end{array}\right]\left[\begin{array}{l}
y_{t-1} \\
p_{t-1}
\end{array}\right]+\left[\begin{array}{l}
e_{y t} \\
e_{p t}
\end{array}\right]
$$

где $e_{t}=\left[\begin{array}{l}e_{y t} \\ e_{p t}\end{array}\right]$, е е от структурных шоков предложения и спроса, $b_{11}(L)$ - элемент $b_{11}$ в матрице $B$.

Чтобы преобразовать уравнение (10) в модель, определяемую уравнениями (7) и (9), остатки векторной авторегрессии ( $e_{t}$ ) должны быть преобразованы в шоки спроса и предложения ( $\left.\varepsilon_{t}\right)$, можно выражать как $e_{t}=C \varepsilon_{t}, \quad$ где $C=\left[\begin{array}{ll}c_{11} & c_{12} \\ c_{21} & c_{22}\end{array}\right]$, это матрица преобразований [8]. Методология оценивания SVAR-модели, представленной в данной работе, соответствует $\mathrm{AB}$-модели, согласно которой $A e_{t}=B \varepsilon_{t}$, то есть $e_{t}=C \varepsilon_{t}=A^{-1} B \varepsilon_{t}$, и можем получить коэффициенты корреляции шоков между странами.

\section{Результаты}

Для анализа применяются годовые показатели за 1990-2020 гг., в качестве эндогенных переменных SVAR-модели используются объем производства и цена. Объем производства измеряется ВВП, выраженным в постоянных долларах США в 2010 году, а цены измеряются индексом - дефлятора ВВП. Все данные взяты из базы данных Всемирного банка ${ }^{10}$. Для достижения цели авторы используют эконометрическую программу Eviews 10, в которой проводят ряд тестов, необходимых для получения статистически нижних результатов по моей модели.

Поскольку используемые данные являются временными рядами, необходимо получить стационарность во всех данных и провести процедуру Augmented-Dickey-Fuller тест (далее ADF-тест). При стационарнасти данных может создать векторную модель авторегрессии. Из-за

\footnotetext{
${ }^{10}$ База данных Мирового банка: https://data.worldbank.org/.
} 
больших различий в данных необходимо взять логарифм ВВП и логарифм дефлятора ВВП, чтобы пройти ADF-тест. Результаты теста приведены в таблицах 3 и 4.

Таблица 3

Результаты ADF-теста объема производства и цены РФ

\begin{tabular}{|c|c|c|c|c|c|}
\hline Показатель & ADF & Значимость (1 \%) & Значимость (5\%) & Значимость (10 \%) & Вероятность принятия \\
\hline LNGDP & $-3,561$ & $-4,297$ & $-3,568$ & $-3,218$ & 0,051 \\
\hline DLNGDP & $-2,590$ & $-2,647$ & $-1,953$ & $-1,610$ & 0,012 \\
\hline D2LNGDP & $-4,462$ & $-2,653$ & $-1,954$ & $-1,609$ & 0,000 \\
\hline LNGDPD & 0,045 & $-4,416$ & $-3,622$ & $-3,248$ & 0,994 \\
\hline DLNGDPD & $-4,501$ & $-4,394$ & $-3,612$ & $-3,243$ & 0,008 \\
\hline D2LNGDPD & $-4,406$ & $-2,653$ & $-1,954$ & $-1,609$ & 0,000 \\
\hline
\end{tabular}

Составлено авторами по результате анализа Eviews 10

Результаты ADF-теста объема производства и цены КНР

Таблица 4

\begin{tabular}{|c|c|c|c|c|c|}
\hline Показатель & ADF & Значимость (1 \%) & Значимость (5\%) & Значимость (10 \%) & Вероятность принятия \\
\hline LNGDP & $-2,434$ & $-3,679$ & $-2,978$ & $-2,623$ & 0,142 \\
\hline DLNGDP & $-1,952$ & $-4,310$ & $-3,574$ & $-3,222$ & 0,602 \\
\hline D2LNGDP & $-5,282$ & $-3,689$ & $-2,972$ & $-2,625$ & 0.000 \\
\hline LNGDPD & $-4,221$ & $-4,309$ & $-3,574$ & $-3,222$ & 0,012 \\
\hline DLNGDPD & $-2,184$ & $-2,653$ & $-1,954$ & $-1,609$ & 0.030 \\
\hline D2LNGDPD & $-5,241$ & $-2,653$ & $-1,954$ & $-1,609$ & 0.000 \\
\hline
\end{tabular}

Составлено авторами по результате анализа Eviews 10

Согласно результату теста, темпы роста BBП (DLNGDP) России стационарны на уровне достоверности $5 \%$, а инфляции (DLNGDPD) России стационарны на уровне достоверности $1 \%$, а темпы роста ВВП Китая нестационарны, а инфляции стационарны на уровне достоверности $5 \%$.

Для поддержания стационарности данных на выборочных данных выполняется дифференциальная обработка, чтобы получить D2LNGDP и D2LNGDPD, то есть это разность темпы роста ВВП и разность инфляции. На уровне достоверности $1 \%$ разности темпы роста BВП и инфляции России и Китая все стационарные, может построить SVAR-модель.

Bo-первых, авторы построили VAR-модель, где эндогенные переменные модели VAR является разности темпы роста ВВП и разности инфляции.

Bo-вторых, прошли поиск оптимальные порядка лага для метода VAR, который выполняется на основе нескольких критериев поиска. Основными считаются значения информационного критерия Акайке (AIC), значения информационного критерия Шварца (SC) и значения информационного критерия Хеннана-Куинна (HQ) [9].

Таблица 5

Информация оптимального порядка лага для модели VAR

\begin{tabular}{|c|c|c|c|c|c|c|c|}
\hline Страна & Lag & LogL & LR & FPE & AIC & SC & HQ \\
\hline \multirow{3}{*}{ РФ } & 0 & 51,93146 & NA & $6,31 \mathrm{e}-05$ & $-3,994517$ & $-3,897007$ & $-3,967472$ \\
& 1 & 59,30477 & $12,97702^{*}$ & $4,83 \mathrm{e}-05^{*}$ & $-4,264381^{*}$ & $-3,971851^{*}$ & $-4,183246^{*}$ \\
& 2 & 60,62939 & 2,119400 & $6,04 \mathrm{e}-05$ & $-0,4050351$ & $-3,562801$ & $-3,915126$ \\
\hline \multirow{3}{*}{ КНP } & 0 & 124,4417 & NA & $1,91 \mathrm{e}-07$ & $-9,795339$ & $-9,697829$ & $-9,768294$ \\
& 1 & 132,4853 & $14,15673^{*}$ & $1,39 \mathrm{e}-07 *$ & $-10,11883^{*}$ & $-9,826297 *$ & $-10,03769^{*}$ \\
& 2 & 135,4215 & 4,697784 & $1,52 \mathrm{e}-07$ & $-10,03372$ & $-9,546166$ & $-9,898490$ \\
\hline
\end{tabular}

Составлено авторами по результате анализа Eviews 10

Следовательно российская и китайская модели VAR с лагом первого порядка. Следующая процедура делать графическое представление корней AR, этот тест предназначен 
для поиска стационарности модели VAR в целом. Модель VAR будет стационарна в том случае, если все корни, по абсолютному значению будут меньше единицы и лежать в единичном кругу. Если же модель не подходит по критерию теста, и один или несколько корней лежат вне круга — данная модель VAR не подходит для исследования, и надо искать другую.

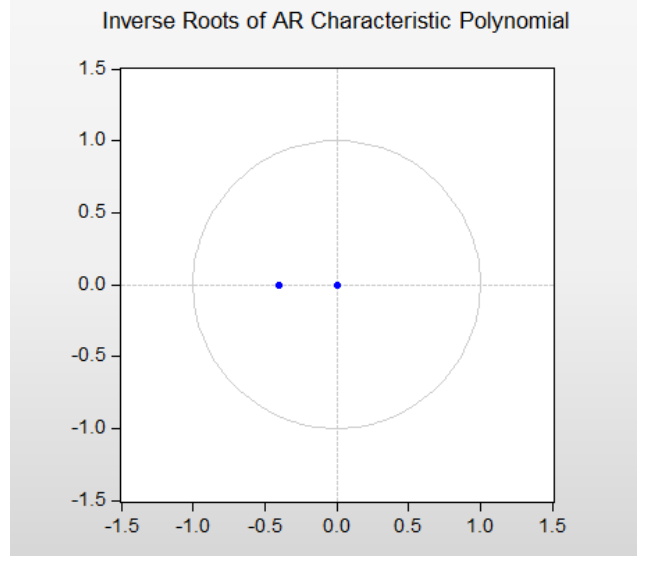

Рисунок 4. Российское графическое представление корней AR (составлено авторами по результате анализа Eviews 10)

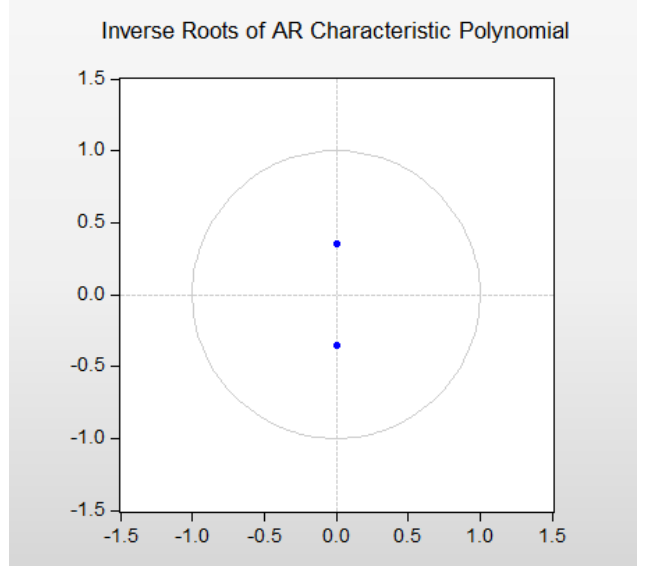

Рисунок 5. Китайское графическое представление корней AR (составлено авторами по результате анализа Eviews 10)

Согласно рисункам 4 и 5, российская и китайская модель VAR стационарны. Авторы представляют долгосрочные ограничения на модель VAR, чтобы получить модель SVAR, a затем продвинуть декомпозиции волатильности, это поиск корреляций между $\varepsilon_{s t}$ и $\varepsilon_{d t}$.

\section{Коэффициенты корреляции шоков между РФ и КНР}

Таблица 6

\begin{tabular}{cc}
\hline корреляции шоков предложения & корреляции шоков спроса \\
\hline 0.1645 & 0.0996 \\
\hline
\end{tabular}

Составлено авторами по результате анализа Eviews 10

Коэффициенты корреляции в таблице отражают корреляции экономик двух стран в случае шока. Величина корреляции отражает разницу между двумя странами в случае шока; положительный и отрицательный коэффициент корреляции - это направление воздействия шока между двумя странами [9].

Согласно таблице 6, с 1990 по 2020 годы корреляции шоки спроса и предложения между Россией и Китаем имеют положительную корреляцию, но ни шок спроса, ни шок предложения не превышают 0,2, свидетельство, что между Россией и Китаем несильная корреляция.

\section{Заключение}

Финансовое сотрудничество между Россией и Китаем достигло больших результатов в построении механизмов сотрудничества, в сфере банковского дела и в сфере расчетов в нацвалютах. Можно считать, что сформированы определенные базовые условия для финансового сотрудничества.

Согласно теории корреляции экономического шока, чем выше корреляции шоков спроса и предложения между различными экономиками, тем ниже стоимость финансового сотрудничества и тем больше возможностей для углубления финансового сотрудничества [10].

С точки зрения экономического шока корреляции спроса и предложения между Россией и Китаем относительно невысоки, означает, что на данной этапе не подходит для углубления российско-китайского финансового сотрудничества в больших масштабах. 
Авторы считают, что Россия и Китай на данном этапе не подходят для крупномасштабного финансового сотрудничества, но, исходя из существующих базовых условий, масштабы сотрудничества в финансовой сфере между двумя странами могут постепенно расширяться в процессе дальнейшего продвижения сотрудничества.

Авторы рекомендуют углублять российско-китайское финансовое сотрудничество со следующих аспектов:

1. Совершенствование механизма финансового сотрудничества. Механизм передачи может быть установлен между механизмами государственного и негосударственного уровня для содействия обмена информацией на всех уровнях и повышения эффективности работы.

2. Повышение уровня двусторонних расчетов в нацвалютах и содействие интернационализацию рубля и юаня. Расчет в нацвалютах следует расширять с приграничных районов на другие районы. Содействовать практическую реализацию интеграции Системы международных платежей Китая (CIPS) с отечественной Системой передачи финансовых сообщений (СПФС), чтобы двусторонний торговый клиринг мог осуществляться напрямую в нацвалютах, и снизить стоимость трансграничных расчетов.

3. Повышение уровня обслуживания банков и внедрение инновации в финансовые продукты. Банки обеих сторон могут развивать корреспондентские отношения и создавать филиалы для расширения географического охвата. Надо активно внедрять инновации в финансовые продукты, обогащать инструменты расчетов между Россией и Китаем и повышать эффективность расчетов.

\section{ЛИТЕРАТУРА}

1. Го Сяоцюн. Российско-китайское финансовое сотрудничество и тенденции развития // Проблемы торгово-экономического сотрудничества российского дольнего востока и северо-востока Китая. — 2019. - Том. Книга I, раздел 3, C. 255-283. — URL: https://elibrary.ru/item.asp?id=41116566 (дата обращения: 12.09.2021).

2. Александрова М.В. Российско-китайское финансово-банковское сотрудничество // Азия и Африка сегодня. - 2016. - № 8. - С. 24-30. - URL: https://www.elibrary.ru/item.asp?id=27173977 (дата обращения: 12.09.2021).

3. Панг Хайфэн. Исследование текущей ситуации, проблем и мер противодействия китайско-российскому финансовому и торговому сотрудничеству / Панг Х., Хоу М., Панг Ш. // Финансы Хэйлунцзяна. — 2019. — № 4. - C. 59-62. — URL: http://www.cnki.com.cn/Article/CJFDTotal-HLJR201902024.htm (дата обращения: 13.09.2021).

4. Курьянова С.Л. Сравнительный анализ создания и функционирования национальных платежных систем на базе пластиковых карт (на примере России и Китая) / С.Л. Курьянова, О.С. Цвигунова // Российско-китайские исследования. — 2019. — T. 3, № 1. - C. 58-67. — URL: https://elibrary.ru/item.asp?id=38567105 (дата обращения: 14.09.2021). 
5. Мазенина Ю.О. Перспективы изменения валютной структуры двухсторонних платежей между Россией и Китаем с учетом межправительственного соглашения о расчетах и платежах // Российский экономический интернет-журнал. - 2019. — № 4. — URL: http://www.e-rej.ru/Articles/2019/Mazenina.pdf (дата обращения: 14.09.2021).

6. Безбородова A.B. SVAR: анализ и прогнозирование основных макроэкономических показателей // Банковский вестник. - 2017. — № S11. C. 3-30. - URL: https://elibrary.ru/item.asp?id=39565352 (дата обращения: 17.09.2021).

7. Blanchard O. and Quan D. The dynamic effects of aggregate demand and supply disturbance. American Economic Review. - 1989. - vol. 79. — № 4. pp. 655-673. URL: https://uh.edu/ bsorense/BlanchardQuah1989.pdf (дата обращения: 17.09.2021).

8. Bayoumi, T., and Eichengreen B. One Money or Many? Analyzing the Prospects for Mon- etary Unification in Various Parts of the world. Princeton studies in internatonal finance. - 1994. - № 76. URL: https://ies.princeton.edu/pdf/S76.pdf (дата обращения: 17.09.2021).

9. Гао Тимэй. Методы эконометрического анализа и моделирование // - Пекин: издательство Университета Цинхуа, 2006. — 535 с. ISBN 9787302117315.

10. Cai T. and Sun J. Research of Economic Foundations of China-ASEAN Monetary Cooperation - A VAR Analysis Based on the Symmetry of Economic Shocks. AsiaPacific Economy. - $2012 . \quad$ № 6. URL: https://en.cnki.com.cn/Article_en/CJFDTotal-YTJJ201206004.htm (дата обращения: 18.09.2021). 


\section{Song Jiaxue \\ Ural Federal University named after the First President of Russia B.N. Yeltsin, Ekaterinburg, Russia

\section{Russian-Chinese financial cooperation: possibility of large-scale deepening}

Abstract. Today, Russia and China are the two largest developing economies in the world, and they are also comprehensive partners of each other, having close ties and cooperation in political, economic, energy and other fields. In recent years, Russia and China have achieved great results in financial cooperation, but in general the situation is still in its infancy. The large-scale deepening of Russian-Chinese financial cooperation is a common interest and an inevitable trend of the two countries.

In this article, the authors first examined the current state of Russian-Chinese financial cooperation. It is established that the two countries have created a two-level mechanism of cooperation, opened several bank branches and representative offices, developed interbank correspondent relations and bilateral settlements in national currencies are developing rapidly, the share of national currencies in settlements between Russia and China in 2020 reached $25 \%$, and in 2013-2014 this share was negligible and amounted to about $2-3 \%$.

The authors also use the SVAR model from the point of view of economic shock correlation to analyze the possibility of large-scale deepening of financial cooperation between Russia and China. It was found that the correlation coefficients of supply shock and demand shock between Russia and China did not exceed 0.2. It is believed that the two countries have basic conditions for financial cooperation, but currently there are no conditions for large-scale deepening of further cooperation in the financial sphere.

In conclusion, the authors recommended deepening Russian-Chinese financial cooperation from the following aspects:

1. Improving the mechanism of financial cooperation.

2. Increasing the level of bilateral settlements in national currencies and promoting the internationalization of the ruble and yuan.

3. Improving the level of banking services and introducing innovations in financial products.

Keywords: financial cooperation; Russia; China; SVAR model; economic shock; offer shock; demand shock; correlation 